\title{
Research on Ability Constitution for Chinese Teachers
}

\author{
Zheng Zhang ${ }^{\mathrm{a}}$, Jun Yang ${ }^{\mathrm{b}}$ \\ School of Education and Sports, Bohai University, Jinzhou, 121013, China \\ a147994621@qq.com, byj690213@126.com
}

Keywords: Chinese teachers; ability constitution; comprehensive quality; teaching ability; professional skills; professional skills; information technology; general ability

\begin{abstract}
Chinese teaching is the foundation of quality education. Chinese teaching should improve the students' Chinese accomplishment and correctly grasp the language characteristics of education, advocate independent and cooperative, inquiry learning style, strive to build open and dynamic Chinese curriculum. Aiming at the present stage the language teacher ability as well as the problems existing in the training process, in this paper, the study of the language teacher competence. Graphically constructed by six primary index and 43 secondary indicators support the language teacher competence framework, and the "comprehensive quality, would ability, professional skills, professional skills and information technology" such as primary index were described in detail. The work of this article, can make the plan of practical ability to improve, to improve the quality of Chinese teachers' ability and language teaching services.
\end{abstract}

\section{Introduction}

"If the country is the foundation of education, the teacher is the cornerstone of founder". Teacher is the professional education teaching responsibilities, to undertake teaching, training builders and successors for the socialist cause, the mission of improving national quality. The teacher's role can be summarized as the following three points: teachers are the convey of knowledge, human culture on the continuation and development of human society have continuity bridge; The teacher is human soul engineer, play a key role for the growth of young generation. Teacher is the organizer and leader of education work, play a leading role in the education process.

"The language is the most important communication tool" that is to say there are many kinds of human communication tools, but the language is the most important. "The language is an important part of human culture, the language is the human culture is considered suitable for teenagers to study in the essence, for the human culture inheritance and the youth. So Chinese teaching should teach students to use this tool, should inherit human culture to promote Chinese teaching teenagers grow up healthily.

Language as a basic subject, open time is long, wide more class time, content, role. Chinese teaching is a complex system, is a science, art, knowledge, skills, and political and other factors of synthesis. The language teacher to the student to conduct a comprehensive quality education, including the ability to develop understanding, training, hands-on skills, teach the language knowledge, scientific and cultural knowledge, develop intelligence, cultivate ideology and moral character, edify sentiment and improve the level of aesthetic spirit [1]. Chinese subject as a basis for other disciplines is also very obvious, the influence of Chinese language teaching to change society, set up the code of ethics, to beautify the social environment and so on all have the effect that cannot ignore. Teacher as a profession, have certain professional nature, must have certain professional knowledge, professional skills and professional quality, these contents constitute the teachers' ability. To study the language teacher competence, to promote the language teacher growth, improve the level of Chinese language teaching plays an important role in such aspects.

\section{Framework on Ability Constitution for Chinese Teachers}

To strengthen teachers team construction, improve the level of ethics and business ability, enhance teachers' sense of honor and responsibility of teaching, it is under the new situation puts forward 
new requirements to teachers. In this world full of challenges and open, with the rapid development of science and technology and the changing of the society, also the profound changes in education itself. New era background and education situation of modern teachers' ability to put forward the severe challenge and higher requirements, in the traditional sense of the teachers' ability has not been able to meet the needs of social development and education. To construct modern "new teachers" ability system embodied in the following ten aspects [2]: a teacher by worthy example ability, learning ability, exploring ability, innovation ability, cooperation ability, communication skills, professional ability, cognitive ability, education and information technology ability. By comprehensive analysis of more than ten kinds of ability and combined with the characteristics of Chinese teaching, to conclude the language teacher competence framework as shown in Fig. 1.

\begin{tabular}{|c|c|}
\hline Comprehensive quality & Information technology \\
\hline Language expression ability & Information basic knowledge \\
\hline Organization management ability & Information systems use \\
\hline Social service ability & Information retrieval ability \\
\hline Scientific research ability & Information integration ability \\
\hline Ideological morality quality & Information processing ability \\
\hline Personality psychological quality & Information communication ability \\
\hline "Teaching ability & General ability \\
\hline Teaching design ability & Communication ability \\
\hline Teaching implementation ability & Cooperation ability \\
\hline After class reflection ability & Adaptive ability \\
\hline Teaching evaluation ability & Creative ability \\
\hline Resource utilization ability & Analytical ability \\
\hline Teaching control ability & Reasoning ability \\
\hline $\begin{array}{c}\text { Professional skills } \\
\end{array}$ & Expression ability \\
\hline Professional basic skills & Imitative ability \\
\hline Professional practical skills & Judgment ability \\
\hline Language literature knowledge & Memory ability \\
\hline Written words ability & Self-control ability \\
\hline Literary creation ability & Strain ability \\
\hline Applied writing ability & Independent ability \\
\hline
\end{tabular}

Fig. 1. Framework on ability constitution for Chinese teachers

\section{Comprehensive Quality}

The comprehensive quality refers to a person's knowledge level and moral cultivation and comprehensive qualities of various kinds of ability, etc. Person's comprehensive quality improving 
is the general requirements and the trend of social development, especially in the current human is about to enter the knowledge economy society, improve the comprehensive quality of people is particularly urgent. Has higher requirements to teachers' comprehensive quality, mainly reflected in the following six aspects: (1) Language expression ability, teachers' Language in addition to follow the general Language requirements, but also has the characteristics of education workers, should not only vivid, accurate, clear, concise, popular, but also rich in a certain emotional, humor, rhythmic and penetrating power, etc; (2) the Organization management ability [3], is refers to the teachers of education activity plan decision-making, Organization, command the ability of supervision and control, and the education teaching organic combination, constitute the whole education system; (3) Social service ability, teacher's role in addition to the teaching and scientific research, to integrate theory with practice, the integrated use of professional theory knowledge to solve practical problems, the use of effective resources, to provide more and better Social services. (4) Scientific research ability, teachers' Scientific research ability is the promotion of connotative development in colleges and universities, improve the teaching quality and strengthen the key social service ability, in the process of Scientific research to constantly find and solve problems, pushing forward the innovation of education theory and education practice; (5) the Ideological morality quality [4], the teacher speaks to politics, upright, study, establish the idea of serving the people, carry forward the spirit of patriotism, collectivism and revolutionary humanitarianism, excellently, selfless dedication, carry forward the traditional virtues of the Chinese nation, has the good professional ethics and a sound democratic legal concept; (6) move psychological quality [5], teachers' psychological quality is an important way to influence and shape the students' harmonious Personality, teacher's Personality psychological quality affects the student non-intelligence factor development, teachers' good Personality quality is beneficial to active classroom atmosphere. So as to maximize the teaching efficiency.

\section{Teaching Ability}

Teaching ability is the main aspect of teachers' professional ability, is an effective power to complete the teaching activities, is a teacher's ability to control the whole teaching process. Teaching ability mainly includes the following six aspects [6, 7]: (1) would design ability, directly affect the level of preparation of Teaching, affect the quality of the Teaching design. Including the design of teaching goal, highlight the important and difficult teaching ability, teaching strategies and teaching methods, such as writing lesson plan ability; (2) would implementation ability, it is flexible for the realization of the designed Teaching scheme effectively organize the Teaching ability, Teaching language concise, vivid, skillfully use blackboard writing, the proper use of multimedia Teaching tools, such as questions appropriately and effectively, strengthen the important and difficult contents, face all and pay attention to individual students; (3) After class reflection ability, the applicability of the selected teaching goals, and according to the goal of the selected teaching strategy's ability to make judgments. Judgment is successfully completed the teaching goal, still need to plan, or try a new strategy; (4) would evaluation ability, pointing to two aspects of Teaching and learning, a refers to teacher's Teaching self-evaluation ability, the ability refers to a student's academic performance evaluation; (5) the Resource utilization ability, teaching Resource is teaching is helpful to the teaching of material resources, financial and human factors, also including some of the students' non-intelligence factors, teachers' moral cultivation, the relationship between teachers and students and teaching mode in the process of teaching. The development and utilization of education resources, can promote the teaching and improve teaching effect; (6) would control ability, it is the ability requirements of the curriculum implementation stages, including Teaching information feedback ability, ability to control the Teaching process and classroom management skills, reasonable regulation of rhythm and content to the class. 


\section{Professional Skills}

Teachers in the teaching activities of the actual display of Professional ability, including the following six aspects[8,9] : (1) Professional basic skills, including knowledge of Chinese language and literature with higher levels of reading writing ability, the language classroom teaching theoretical knowledge and proficient in the language classroom teaching skills and ability; (2) Professional practical skills, in recent years, the "double teachers" team construction has become the consensus and obtained a certain result, the language teacher must improve their Professional skills to meet the need of cultivation of talents and teaching reform. (3) Language literature knowledge, including basic theory and basic knowledge of Chinese Language and literature, education and teaching research of basic training, has the good cultural accomplishment and the professional quality of teachers engaged in the professional ability in the teaching and scientific research ability; (4) Written words ability, namely the correct specification to write an hour. than play games, chalk and Chinese calligraphy, especially chalk writing will directly affect the teaching effect. Because correct, fluent, beautiful, neat and clear chalk, subtly influence not only the students, also can make students produce a kind of admiration, set up image in the eyes of students, make the student to teacher produces a kind of psychological identity; (5) The Literary creation ability, Literary creation is a complex special spirit production, is the life of aesthetic experience, through art processing produce available for readers to appreciate the Literary works of creative activity. Literary creation is one of the important standards reflect the language teachers' professional skills, the language teacher's understanding of life not only limited to the rational level, should be properly promoted to the perceptual level, express the feeling of life with different style; (6) Applied writing ability, practical writing is in the work, study and life, in order to deal with all kinds of public and private affairs, message communication, to solve practical problems, to use has a direct practical value, format specification, and language ability of contracted a variety of style of writing. Social higher request for the Chinese teachers' practical writing ability.

\section{Information Technology}

Modern information technology to text, graphics, images, video, images, animation, and sounds, such as delivery information media together, through the computer integrated treatment and control, the screen will be organic combination of various elements of a variety of media, and completed a series of random interactive operation, make the class content from static to instill into graphic dynamic transmission of audio and video content, enhances the appeal, is helpful for students to expand knowledge, strengthen scientific teaching and linked to the actual life, let students experience and learn about everything important in life science, experience the fun of learning science, actively explore the valuable knowledge of science, in the process of learning to explore the cultivating creative ability, so as to improve the efficiency of classroom teaching, promote the all-round development of students' quality [10]. Chinese teacher Information technology ability is mainly embodied in the following six aspects [11]: (1) Information, basic knowledge, including knowledge of computer hardware, software and network knowledge, etc.; (2) Information systems use, including installation and start the hardware system, operating system software and hardware, computer system daily maintenance, judge and estimates the cause of the failure and make the necessary processing, etc.; (3) Information retrieval ability, using a variety of ways to find out useful Information from the numerous Information ability, including both simple keyword queries, including advanced complex search capabilities; (4) Information integration ability, it is all sorts of Information filtering and analysis, optimum combination, comprehensive utilization, processing innovation and create a kind of ability; (5) Information processing ability, from Information gathering to release Information of the whole process, including Information gathering, processing, storage, Information, publishing Information and evaluation Information and other steps; (6) Information communication ability, it is a kind of ability of Information sharing activity, in the Information technology makes the communication channels between teachers and students grow in quantity, exchange time extended. 


\section{Conclusion}

Chinese curriculum should inspire and cultivate the thoughts and feelings of the students love the motherland language, guides the student to enrich language accumulation, cultivate language sense, the development of thinking, the preliminary master the basic methods to learn language, develop good study habits, have to adapt to the real life need to read and write ability, reading ability, writing ability and oral communicative ability, the correct use of native language. Chinese curriculum should also through excellent culture of infection, promote the harmonious development of students, make them improve ideological and moral cultivation and aesthetic temperament and interest, gradually form a good personality and sound personality. The language teacher ability and has important effect on language teaching, education departments, schools and teachers' individual can refer to this article research results, practical ability to improve planning, to improve the quality of Chinese teachers' ability and language teaching services.

\section{Acknowledgement}

This work is supported by social science fund project of Liaoning province (L13CZZ044): Phenomenon analysis and countermeasure research on 'vulgarization' for college students' life world; A-class teaching reform project of Bohai university in 2014: Path study on normal students in teachers' professional ability training on the background of state test of teachers' qualification; 2014 annual "A" class teaching reform project in education department of Liaoning province (UPRP20140249).

\section{References}

[1] L. Xia, "Under teacher specialization background Chinese teacher's ability constitution and its self-raise," Master's degree of Hunan Normal University, 2006.

[2] Y. C. Chen, "Modern teachers should have ten kinds of ability," Shangqiu daily: http://www.sqrb.com.cn/sqnews/2014-04/18/content_2340023.htm, 2016-3-12.

[3] Y. W. Zhang, "On Teachers' organization and management ability," Journal of shanxi finance and economics university, vol. 22, no. s1, pp. 198, 2000.

[4] C. J. Li, "On the quality of Ideological and moral teachers in the stage of compulsory education," Reading, writing, and arithmetic, vol. 29, no. 16, pp. 123-124, 2013.

[5] H. G. Cai, "On Teachers' Individual Psychological Quality and Student Development," Journal of Huaihai Institute of Technology (Social Science Edition), vol. 8, no. 3, pp. 124-125, 2010.

[6] F. Wang, "Evaluation criteria of primary school language teachers' teaching ability," Journal of Liaoning Educational Administration Institute, vol. 28, no. 9, pp. 150-152, 2010.

[7] Higher Education Research and Evaluation Center, Southwest University of Science and Technology , "The teaching ability of university teachers," http://www.pgzx.swust.edu.cn/s/83/t/854/a/35096/info.htm, 2016-3-12.

[8] West snow' blog, "Chinese teachers' professional knowledge and skills," http://blog.sina.com.cn/s/blog_4787ac670102e7i4.html, 2016-3-12.

[9] C. H. Ye, W. Y. Zhu, "On the cultivation of teachers' professional practice skills in Higher Vocational Colleges," Super science, vol. 15, no. 3, pp. 117-118, 2011.

[10] Baidu Wenku, "Information technology ability learning experience," http://wenku.baidu.com/link?url=66evl5YrtvJEeKNq, 2016-3-12.

[11] Y. Q. Yan, "Research on the Training Content of the System of school teachers on Information technology capabilities," Master's degree of Northwest normal university, 2009. 